(c) American Dairy Science Association, 2007.

\title{
Two- or Four-Hour Lying Deprivation on the Behavior of Lactating Dairy Cows
}

\author{
M. D. Cooper, ${ }^{\star} \dagger$ D. R. Arney, ${ }^{\star}$ and C. J. C. Phillips ${ }^{\star}+\ddagger^{1}$ \\ *Moulton College, Northampton, UK \\ †Department of Clinical Veterinary Medicine, University of Cambridge, UK \\ $\ddagger$ School of Veterinary Science, University of Queensland, Australia
}

\section{ABSTRACT}

Cows are often temporarily deprived of the opportunity to lie down while waiting for veterinary or reproductive procedures. Sixty cows were deprived of the opportunity to lie down for 0,2 , or $4 \mathrm{~h}$ by confining them in pairs in a small indoor pen. Behavior was recorded during deprivation and for $40 \mathrm{~h}$ afterwards. In the first 2 and $4 \mathrm{~h}$ of the experiment, cows that were not deprived chose to lie down for 70 and $142 \mathrm{~min}$, respectively. When cows were discouraged from lying, they regularly stomped their legs, repositioned themselves, but never lay down. In the 4-h treatment, both stomping and repositioning increased after the first hour. Butting and weight shifting (displacing weight from one side of the body to the other) increased during deprivation, indicating restlessness. Cows deprived for $4 \mathrm{~h}$ sniffed and rubbed their heads against the housing more than cows deprived for 0 or $2 \mathrm{~h}$. Time spent feeding and standing without ruminating increased with the duration of deprivation, especially during the early stages; standing ruminating also increased in the final stages. After deprivation, feeding time decreased, which compensated for the increase during deprivation. By $40 \mathrm{~h}$ after deprivation, the lying-deprived cows had recovered approximately $40 \%$ of their lost lying time. Milk yield was not affected by lying deprivation. It is concluded that cows experience discomfort during short periods of lying deprivation, after which they recover some, but not all, of the lost lying time by rescheduling feeding and standing time.

Key words: dairy cow, behavior, lying, feeding

\section{INTRODUCTION}

Satisfying the motivation to lie down is important for the well being of dairy cows (Metz, 1985; Wierenga and Hopster, 1990; Munksgaard et al., 1999). Cattle show a strong motivation for lying (Metz, 1985; Wierenga

Received March 6, 2006.

Accepted October 27, 2006.

${ }^{1}$ Corresponding author: c.phillips@uq.edu.au and Hopster, 1990; Hopster et al., 2002). Heifers approximately 3-mo pregnant have a strong demand for 12 to $13 \mathrm{~h}$ of lying per $24 \mathrm{~h}$ (Jensen et al., 2005).

Lying deprivation can have negative effects on the welfare of dairy cows, as evidenced by stress physiology. Cows repeatedly deprived of lying had greater ACTH concentrations at the beginning and end of a 14-h deprivation period (Munksgaard and Simonsen, 1996), suggesting that the procedure is stressful and that the cow is unable to adapt during this period. Repeated lying deprivation increased the cortisol response to an ACTH challenge (Munksgaard et al., 1999). Growth hormone concentrations were reduced in cattle deprived of lying for $14 \mathrm{~h} / \mathrm{d}$ during several weeks (Munksgaard and Lovendahl, 1993; Ingvartsen et al., 1999), which could reduce milk yield because growth hormone is galactopoietic (Hart, 1988; Munksgaard and Lovendahl, 1993). Short lying times also can predispose cows to sole hemorrhage (Singh et al., 1993).

Both physical and physiological factors can compromise the amount of time available for lying. There is a negative relationship between lying time and milk yield in grazing dairy cows (Castle and Halley, 1953), because high-yielding cows require more grazing time, and, as a consequence, have less time available to lie down. Similarly, high-yielding cows have shorter lying times but longer feeding times while indoors compared with low-yielding cows (Fregonesi and Leaver, 2001). Cows in early lactation spend less time lying than cows in late lactation and dry cows (Veris et al., 1980; Chaplin and Munksgaard, 2001). The conditions in which dairy cows are housed can also affect lying behavior. For example, the lying time of cows in freestalls is reduced in proportion to the degree of overcrowding (Wierenga and Hopster, 1990). Cows housed in straw yards lie down for longer than those in freestalls (Phillips and Schofield, 1994; Fregonesi and Leaver, 2001). Individually housed cows lie down longer if they are in a large pen with mattress flooring compared with when they are in tie stalls (Haley et al., 2000). In addition, routine farm procedures, such as AI, can increase standing time. In New Zealand, farmers remove cows from pasture during periods of heavy rainfall to avoid damage 
to the pastures and confine them in concrete-surfaced pens. In the pens, they are deterred from lying on the hard surface and spend more time standing (Fisher et al., 2003).

Previously cited studies have deprived cows of lying for long periods, which may not be representative of current farm practices. The aim of this study, therefore, was to determine whether a short-term reduction in lying time affects the behavior of lactating dairy cows. Behavioral indicators were used to reveal any displacement or rebound activities, which are regarded by some as reliable indicators of the emotions that a cow experiences (Munksgaard and Simonsen, 1996).

\section{MATERIALS AND METHODS}

An experiment was conducted over 20 consecutive days, commencing May 13 and ending June 1, using 60 cows from the Holstein-Friesian dairy herd of Moulton College (Northampton, UK). The herd grazed a 4.74ha pasture between 0900 and $1700 \mathrm{~h}$ with ad libitum access to drinking water and an Italian ryegrass pasture (Lolium multiflorum) at the recommended surface height of 8 to $10 \mathrm{~cm}$ (Chamberlain and Wilkinson, 1996). During the remaining $4 \mathrm{~h}$, cows were housed indoors in a large, naturally lit, straw-bedded building $(70 \times 15$ $\mathrm{m})$ with access to drinking water and a TMR (41.1\% corn silage, $27.4 \%$ grass silage, $16.6 \%$ concentrate pellets, $7.8 \%$ corn gluten, $3.9 \%$ molasses-sugar beet, $2.9 \%$ lucerne pellets, and $0.3 \%$ minerals). Feed was delivered once daily during the morning milking using a mixer wagon. Sufficient chopped straw was provided daily to keep the bed surfaces clean. During periods of darkness, artificial lighting was provided at both ends of the shed. All cows were milked twice daily, from 0530 to $0700 \mathrm{~h}$, and 1600 to $1730 \mathrm{~h}$, and $1 \mathrm{~kg}$ of concentrate (Grassmaster 18, Heygates Ltd., Northampton, UK) was offered during milking.

Cows were assigned randomly to 10 blocks of 6 cows each. These 6 cows were then allocated randomly to 3 pairs, and each pair was assigned randomly to 1 of 3 treatments: control (no lying deprivation), $2 \mathrm{~h}$ of lying deprivation, or $4 \mathrm{~h}$ of lying deprivation. Mean initial milk yield was $24.1 \pm 1.6 \mathrm{~kg} / \mathrm{d}$, mean BCS (using a 5point scoring system; Lowman et al., 1973) was $2.92 \pm$ 0.11 , median lactation duration was $255 \pm 21 \mathrm{~d}$, and mean time to next parturition was $124 \pm 13 \mathrm{~d}$.

Each pair was allocated to 1 of 3 adjacent, identical pens (Figure 1) at random, where the necessary treatments were applied. Pens provided ad libitum access to drinking water and the same TMR as the rest of the herd, which was delivered at the same time. During periods of darkness, artificial lighting was provided overhead by 6 strip lights to facilitate video recording.

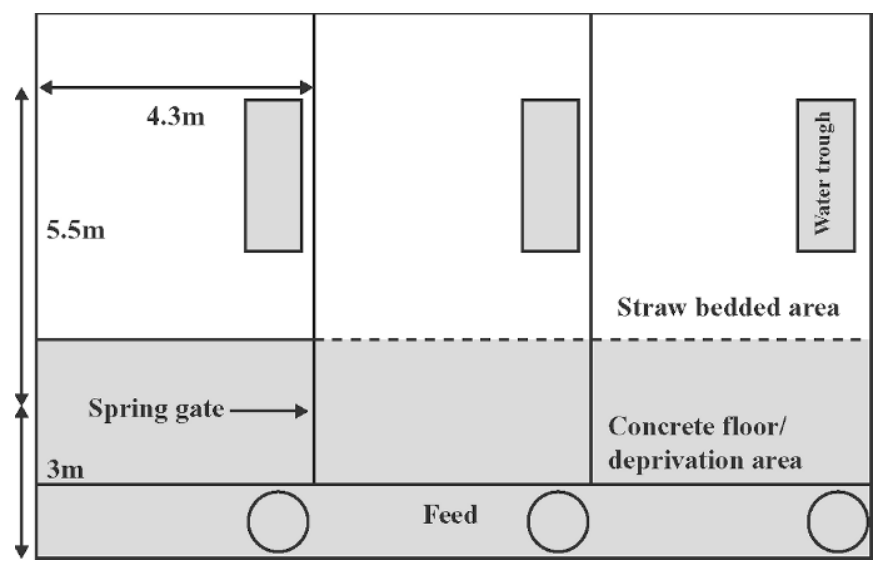

Figure 1. Plan of experimental pens for pairs of cows in the control, 2 -h, and 4-h lying-deprivation treatments. Circles indicate water bowls available to lying-deprived cows during deprivation.

Cows spent $48 \mathrm{~h}$ in the experimental pens and were returned to the herd toward the end of morning milking when a new group of 6 cows was selected. The experimental cows were allowed approximately $3 \mathrm{~h}$ to become accustomed to the pens and each other before any behavioral observations took place. Lying deprivation was achieved by securing the cows in the deprivation area using a nonelectrified spring gate, which prevented the cows from having access to the straw bedded area. The 4- and 2-h deprivation periods commenced at 1020 and $1220 \mathrm{~h}$, respectively, with the 2-h deprivation being applied during the third and fourth hour. At $1420 \mathrm{~h}$ the spring gates were removed and the cows gained access to the bedded area. Following application of treatments, the cows remained as pairs for an additional $41 \mathrm{~h}$, after which they were returned to the herd.

\section{Behavioral Observations}

During Lying Deprivation. Cows were observed in the same order within and between treatments each time by 1 of 3 trained observers. Behaviors considered to be associated with discomfort were recorded using continuous recording, which measured the frequency and duration of each behavior pattern as it occurred. Like bouts were separated from one another when the cow showed a different behavior for at least $1 \mathrm{~s}$.

Behaviors recorded continuously by frequency during the lying-deprivation period included 1) leg stomping (lifting hoof and replacing in same area without forward movement; Houpt et al., 2001); 2) repositioning (moving all 4 legs slowly forward one at a time in a synchronized manner covering less than 1 body length in distance); 3 ) butting (use of head to displace conspecific by physical contact); 4) head swinging (swinging of head either up- 
wards or sideways); 5) weight shifting (displacing weight from one side of the body to the other by either relaxing one leg or shuffling the legs); 6) grooming self (licking any part of the body), or any part of the housing facility; and 7) rubbing head against housing (scratching movement of the head against any part of the housing, especially walls and gates). Behaviors recorded by duration were sniffing (short inspiratory breaths) the ground and housing. Behaviors recorded by scan sampling every 5 min included feeding, ruminating lying or standing, and standing or lying not ruminating.

Video Observations After Lying Deprivation. Continuous time-lapse video recordings (HS-1024EB video recorder, VHS Mitsubishi, Hatfield, UK; 3372 camera, Sanyo, Watford, UK) commenced immediately after the deprivation period and continued for the subsequent $40 \mathrm{~h}$ when the cows remained as pairs in a separate pen isolated from the herd, during which time it was expected that residual or compensatory behavioral effects of treatment would most likely be displayed (Metz, 1985). Recordings of lying, standing, and feeding behavior were made every $5 \mathrm{~min}$, except when the cows were being milked. The latency to the first lying bout was recorded for each cow, and if a cow was already lying, her latency was recorded as zero.

\section{Milk Production}

Milk yield was recorded manually on 4 consecutive occasions for each cow after entering the experiment: afternoon milking on $\mathrm{d} 1$ (deprivation day), morning and afternoon milking on $\mathrm{d} 2$, and morning milking on $\mathrm{d} 3$, before the cows were returned to the herd.

\section{Statistical Analyses}

The computer package Minitab (Minitab Inc., State College, PA) was used for all statistical analyses. Several behaviors recorded during the experiment were not normally distributed according to the AndersonDarling test; therefore, all behaviors were analyzed for statistical differences between treatments using Friedman's nonparametric test of treatment differences, incorporating the pair replicates as blocks. Pair replicates were calculated as mean values. For the postdeprivation video observations, graphical representation of the mean time spent in each behavior for each treatment revealed that 8-h periods were most appropriate for analysis, which was also by Friedman's test, incorporating the pair replicates as blocks. Latency to first lying post-deprivation was not normally distributed and was analyzed by Friedman's test, incorporating the pair replicates as blocks.
Correlation coefficients were determined for behavior variables, separately for the cows in each treatment to avoid treatment effects. Spearman's ranked correlations were selected because some variables were not normally distributed. The correlations chosen were those that might help to determine links between behaviors that may indicate motivational states.

Milk yield was tested for treatment differences by using a generalized linear model, with treatment ( $2 \mathrm{df}$ ), block (replicate, $9 \mathrm{df}$ ), and an error term (18 df) in the model, as the values for each treatment were normally distributed according the Anderson-Darling test and all treatments had equal variance. All data for all treatment combinations were homogeneous.

\section{RESULTS}

\section{Behavior}

Continuous Recordings During Lying Deprivation. Leg stomping was not observed to any major extent by control cows (Table 1), but it increased during the second hour in the 4-h deprivation treatment and during the third and fourth hours in the 4-h treatment, and to a lesser extent in the 2-h treatment. Repositioning and weight shifting were mainly observed when the cows in the 2- and 4-h treatment were deprived of lying, but were not observed to any major extent in control cows or in the 2-h treatment when cows were not deprived of lying. Both behaviors progressively increased with time of deprivation for cows in 4-h treatment, and the median value for all hours increased with the duration of deprivation. Although head swinging was rarely observed in any treatment, it increased $(P<0.05)$ overall with duration of deprivation.

An increase $(P<0.001)$ occurred in the combined restlessness behaviors (leg stomping, repositioning, weight shifting, and head swinging) during the first hour of deprivation for cows in both treatments compared with the control, and there was a tendency for a progressive increase over the period of deprivation. For the 2 treatments and the control together, the combined restlessness behaviors increased $(P<0.001)$ with deprivation length.

Sniffing the housing was rarely observed, but was performed most frequently by cows in 4-h treatment during the fourth hour. Sniffing the ground was reduced in the third hour in this treatment and was reduced overall with duration of deprivation. Rubbing the head against the housing was greatest in the 4-h treatment during the second hour. Self grooming was not affected by treatment, and butting was performed most frequently by cows in 4-h treatment during the first, third, and fourth hours, and increased $(P<0.01)$ overall with length of deprivation. 
Table 1. Median frequency of each behavior recorded continuously during $4 \mathrm{~h}$ for cows in control, 2-h, or 4-h lying-deprivation treatments

\begin{tabular}{|c|c|c|c|c|c|}
\hline \multirow[b]{2}{*}{ Treatment } & \multicolumn{4}{|c|}{ Hour } & \multirow{2}{*}{$\begin{array}{l}\text { Median value/ } \\
\text { for all } 4 \mathrm{~h}\end{array}$} \\
\hline & 1 & 2 & 3 & 4 & \\
\hline \multicolumn{6}{|c|}{ Leg stomping, occurrences/h } \\
\hline Control & 0.1 & 0 & 0.3 & 0 & 0.2 \\
\hline 2 -h & 0.1 & 0.3 & 1.7 & 2.0 & 1.9 \\
\hline 4-h & 0.4 & 3.0 & 2.6 & 3.3 & 2.8 \\
\hline$P$ & 0.33 & 0.001 & 0.003 & 0.004 & 0.001 \\
\hline \multicolumn{6}{|c|}{ Repositioning, occurrences/h } \\
\hline Control & 0 & 0 & 0 & 0.3 & 0 \\
\hline $2-\mathrm{h}$ & 0 & 0.17 & 3.1 & 3.4 & 1.2 \\
\hline 4-h & 2.0 & 3.8 & 4.4 & 5.2 & 3.2 \\
\hline$P$ & 0.001 & 0.003 & 0.001 & $<0.001$ & $<0.001$ \\
\hline \multicolumn{6}{|c|}{ Weight shifting, occurrences/h } \\
\hline Control & 0.25 & 0.25 & 0.63 & 0.25 & 0.19 \\
\hline 2 -h & 0 & 0.33 & 3.9 & 4.3 & 2.3 \\
\hline 4-h & 2.1 & 4.4 & 6.4 & 7.4 & 6.0 \\
\hline$P$ & 0.001 & 0.001 & $<0.001$ & $<0.001$ & $<0.001$ \\
\hline \multicolumn{6}{|c|}{ Head swinging, occurrences/h } \\
\hline Control & 0.42 & 0 & 0 & 0 & 0.25 \\
\hline 2 -h & 0.25 & 0 & 0 & 0.1 & 0.33 \\
\hline 4-h & 0.58 & 0.5 & 0 & 0.17 & 0.48 \\
\hline$P$ & 0.28 & 0.50 & 0.16 & 0.06 & 0.04 \\
\hline \multicolumn{6}{|c|}{ Restlessness behaviors, ${ }^{1}$ occurrences $/ \mathrm{h}$} \\
\hline Control & 1.4 & 1.5 & 0.25 & 0.67 & 0.69 \\
\hline $2-\mathrm{h}$ & 0.5 & 1.9 & 8.7 & 13.3 & 6.69 \\
\hline 4-h & 9.1 & 16.0 & 13.1 & 20.8 & 15.8 \\
\hline$P$ & $<0.001$ & 0.002 & 0.001 & $<0.001$ & $<0.001$ \\
\hline \multicolumn{6}{|c|}{ Sniffing housing, s/h } \\
\hline Control & 0.5 & 0.25 & 0.17 & 0 & 0.5 \\
\hline $2-\mathrm{h}$ & 0.5 & 0.4 & 0.3 & 0.2 & 0.6 \\
\hline 4-h & 0.5 & 0.60 & 0.3 & 0.8 & 0.7 \\
\hline$P$ & 0.31 & 0.68 & 0.45 & 0.05 & 0.40 \\
\hline \multicolumn{6}{|c|}{ Sniffing ground, $\mathrm{s} / \mathrm{h}$} \\
\hline Control & 1.1 & 0.8 & 0.8 & 0.5 & 0.71 \\
\hline 2 -h & 1.1 & 1.2 & 0.8 & 0.3 & 0.54 \\
\hline 4-h & 0.4 & 0.8 & 0.3 & 0.3 & 0.38 \\
\hline$P$ & 0.10 & 0.63 & 0.05 & 0.49 & 0.05 \\
\hline \multicolumn{6}{|c|}{ Rubbing head against housing, occurrences/h } \\
\hline Control & 0.7 & 0.1 & 0.5 & 0.3 & 0.5 \\
\hline $2-\mathrm{h}$ & 0.3 & 0 & 0.9 & 0.3 & 0.7 \\
\hline 4-h & 0.4 & 1.2 & 1.0 & 0.3 & 0.9 \\
\hline$P$ & 0.44 & 0.05 & 0.55 & 0.32 & 0.31 \\
\hline \multicolumn{6}{|c|}{ Grooming self, occurrences/h } \\
\hline Control & 1.3 & 0.8 & 2.5 & 1.5 & 1.0 \\
\hline $2-\mathrm{h}$ & 1.2 & 0.8 & 1.0 & 0.4 & 0.9 \\
\hline 4-h & 1.3 & 1.3 & 1.0 & 0.6 & 1.1 \\
\hline$P$ & 0.97 & 0.23 & 0.60 & 0.78 & 0.29 \\
\hline \multicolumn{6}{|c|}{ Butting, occurrences/h } \\
\hline Control & 0 & 0 & 0.04 & 0 & 0 \\
\hline 2 -h & 0.13 & 0 & 0.13 & 0.17 & 0.15 \\
\hline 4-h & 0.54 & 0 & 0.46 & 0.33 & 0.33 \\
\hline$P$ & 0.01 & 0.78 & 0.04 & 0.02 & 0.003 \\
\hline
\end{tabular}

${ }^{1}$ Leg stomping, leg repositioning, weight shifting, and head swinging.

Within treatment, head swinging was positively correlated $(P<0.05)$ with butting in the 2 -h treatment (Table 2$)$ and negatively correlated $(P<0.05)$ with weight shifting in the control and 2 -h treatments. Leg stomping was positively correlated $(P<0.05)$ with head swinging and negatively correlated $(P<0.05)$ with repositioning in the 4-h treatment. Licking self was positively correlated $(P<0.05)$ with head rubbing in the treated cows. Sniffing the ground was positively correlated $(P<0.05)$ with licking self and weight shifting in all treatments.

Instantaneous Recordings During Lying Deprivation. Time spent feeding was increased $(P<0.05)$ during the first, second, and fourth hours for cows in the 4-h treatment, and during the last hour for cows in the 2-h treatment (Table 3). Overall feeding time 
Table 2. Spearman's rank correlation coefficients for behaviors in control, 2-h, or 4-h lying-deprivation treatments

\begin{tabular}{lccc}
\hline & \multicolumn{3}{c}{ Treatment } \\
\cline { 2 - 4 } Behavior & Control & 2 -h & $4-\mathrm{h}$ \\
\hline Head swinging & - & $0.44^{*}$ & 0.06 \\
$\quad$ with butting & $-0.48^{*}$ & $-0.66^{*}$ & 0.19 \\
$\quad$ with weight shifting & -0.06 & 0.16 & $0.49^{*}$ \\
Leg stomping & - & -0.22 & $-0.48^{*}$ \\
$\quad$ with head swinging & & & \\
$\quad$ with repositioning & 0.09 & $0.49^{*}$ & $0.66^{*}$ \\
Licking self & & & \\
$\quad$ with head rubbing & $0.54^{*}$ & $0.48^{*}$ & $0.49^{*}$ \\
Sniffing ground & $0.78^{*}$ & $0.56^{*}$ & $0.64^{*}$ \\
$\quad$ with licking self & & & \\
with weight shifting & &
\end{tabular}

$* P<0.05$.

increased $(P<0.01)$ with duration of deprivation. Standing not ruminating was increased $(P<0.001)$ during deprivation in both treatments, with the greatest increase being during in the first $2 \mathrm{~h}$ of deprivation. Standing ruminating was increased during the last 3 $\mathrm{h}$ of deprivation for cows in the 4-h treatment and during the last $2 \mathrm{~h}$ for cows in the 2 -h treatment. The greatest increases occurred during the last $2 \mathrm{~h}$ for cows in the 4-h treatment and during the last hour (second hour of deprivation) for cows in the 2 -h treatment. Overall, time spent lying or lying ruminating was approxi- mately halved for cows in the 2-h treatment compared with control cows. Neither behavior was observed in cows in the 4-h treatment, or during the deprivation period in the 2-h period. Overall, ruminating behavior was influenced by treatments, because the proportion of time spent ruminating (both lying and standing) decreased among treatments with increasing deprivation time (38, 28, and $23 \%$ for control, 2 -h, and 4-h cows, respectively).

Post-Lying Deprivation Video Observations. Cows in the 2 - and 4 -h treatments spent less $(P<0.01)$ time feeding during the first $8 \mathrm{~h}$ postdeprivation (Table 4). The greatest difference in feeding time between the cows in the lying-deprived treatments and the control was during the first hour postdeprivation $(1425 \mathrm{~h})$ and the first hour postmilking (1725 h; Figure 2). During the entire $40 \mathrm{~h}$ after deprivation, no difference in feeding time was detected among treatments. It was estimated that the 2- and 4-h deprived cows fed for $25 \mathrm{~min}$ longer, respectively, during the deprivation period and fed for 34 min less, respectively, in the postdeprivation period, than control cows. Compensation for increased feeding during the deprivation period was approximately complete by the end of the 40 -h postdeprivation period.

Cows in the 4-h treatment tended $(P=0.09)$ to spend less time standing (Figure 3; Table 4$)$ and more $(P<$

Table 3. Average duration of each behavior recorded instantaneously every 5 min during $4 \mathrm{~h}$ for cows in control, 2-h, or 4-h lying-deprivation treatments

\begin{tabular}{|c|c|c|c|c|c|}
\hline \multirow[b]{2}{*}{ Treatment } & \multicolumn{4}{|c|}{ Hour } & \multirow{2}{*}{$\begin{array}{l}\text { Total time for } \\
\text { all } 4 \mathrm{~h}, \mathrm{~min}\end{array}$} \\
\hline & 1 & 2 & 3 & 4 & \\
\hline \multicolumn{6}{|l|}{ Feeding } \\
\hline Control & 15.2 & 9.4 & 13.8 & 10.8 & 58.8 \\
\hline $2-\mathrm{h}$ & 19.8 & 11.0 & 23.2 & 17.5 & 73.6 \\
\hline 4-h & 25.6 & 19.0 & 16.7 & 21.7 & 94.4 \\
\hline$P$ & 0.04 & 0.03 & 0.38 & 0.05 & 0.01 \\
\hline \multicolumn{6}{|c|}{ Standing, not ruminating } \\
\hline Control & 7.5 & 8.1 & 7.5 & 7.5 & 32.0 \\
\hline $2-\mathrm{h}$ & 12.5 & 14.4 & 21.3 & 23.8 & 72.4 \\
\hline 4-h & 26.3 & 28.1 & 18.8 & 17.5 & 96.8 \\
\hline$P$ & 0.02 & 0.001 & 0.007 & 0.008 & 0.001 \\
\hline \multicolumn{6}{|c|}{ Standing ruminating } \\
\hline Control & 0 & 0 & 0 & 2.5 & 3.6 \\
\hline $2-\mathrm{h}$ & 0.8 & 0.8 & 8.8 & 20.0 & 33.2 \\
\hline 4-h & 1.7 & 6.7 & 18.8 & 22.5 & 52.0 \\
\hline$P$ & 0.25 & $<0.001$ & $<0.001$ & $<0.001$ & $<0.001$ \\
\hline \multicolumn{6}{|c|}{ Lying, not ruminating } \\
\hline Control & 12.9 & 16.7 & 14.2 & 13.1 & 58.4 \\
\hline $2-\mathrm{h}$ & 8.3 & 13.3 & 0 & 0 & 26.8 \\
\hline 4-h & 0 & 0 & 0 & 0 & 0 \\
\hline$P$ & 0.004 & 0.001 & $<0.001$ & $<0.001$ & $<0.001$ \\
\hline \multicolumn{6}{|c|}{ Lying ruminating } \\
\hline Control & 11.7 & 27.5 & 27.1 & 22.5 & 84.0 \\
\hline $2-\mathrm{h}$ & 9.6 & 18.8 & 0 & 0 & 33.2 \\
\hline 4-h & 0 & 0 & 0 & 0 & 0 \\
\hline$P$ & 0.007 & 0.001 & $<0.001$ & $<0.001$ & $<0.001$ \\
\hline
\end{tabular}


Table 4. Mean time spent feeding, standing, and lying every $8 \mathrm{~h}$, during the first $40 \mathrm{~h}$ immediately following lying deprivation for cows in the control, 2-h, and 4-h lying-deprivation treatments

\begin{tabular}{lrrrr}
\hline & \multicolumn{3}{c}{ Treatment } \\
\cline { 2 - 3 } $\begin{array}{l}\text { Hours postdeprivation } \\
\text { (actual time) }\end{array}$ & Control & $2 \mathrm{~h}$ & $4 \mathrm{~h}$ & \\
\cline { 2 - 4 } Feeding & \multicolumn{4}{c}{ min } \\
\cline { 2 - 4 } 1 to $8(1425$ to $2220 \mathrm{~h})$ & 107 & 77 & 64 & 0.004 \\
9 to $16(2225$ to $0620 \mathrm{~h})$ & 13 & 15 & 11 & 0.57 \\
17 to $24(0625$ to $1420 \mathrm{~h})$ & 86 & 76 & 89 & 0.44 \\
25 to $32(1425$ to $2220 \mathrm{~h})$ & 107 & 99 & 106 & 0.74 \\
33 to $40(2225$ to $0625 \mathrm{~h})$ & 20 & 25 & 25 & 0.77 \\
Total 40 -h period & 311 & 274 & 279 & 0.31 \\
Standing & & & & \\
1 to $8(1425$ to $2220 \mathrm{~h})$ & 100 & 110 & 76 & 0.09 \\
9 to $16(2225$ to $0620 \mathrm{~h})$ & 25 & 30 & 28 & 0.67 \\
17 to $24(0625$ to $1420 \mathrm{~h})$ & 84 & 83 & 87 & 0.99 \\
25 to $32(1425$ to $2220 \mathrm{~h})$ & 89 & 94 & 83 & 0.91 \\
33 to $40(2225$ to $0625 \mathrm{~h})$ & 28 & 31 & 29 & 0.71 \\
Total 40 -h period & 356 & 338 & 310 & 0.53 \\
Lying & & & & \\
1 to $8(1425$ to $2220 \mathrm{~h})$ & 206 & 231 & 271 & 0.04 \\
9 to $16(2225$ to $0620 \mathrm{~h})$ & 438 & 440 & 442 & 0.58 \\
17 to $24(0625$ to $1420 \mathrm{~h})$ & 231 & 227 & 238 & 0.91 \\
25 to $32(1425$ to $2220 \mathrm{~h})$ & 217 & 229 & 213 & 0.72 \\
33 to $40(2225$ to $0625 \mathrm{~h})$ & 435 & 436 & 423 & 0.50 \\
Total 40 -h period & 1,511 & 1,535 & 1,579 & 0.20 \\
\hline
\end{tabular}

0.05) time lying (Figure 4; Table 4) during the first 8 $\mathrm{h}$ postdeprivation than did control or 2-h deprived cows. Latency to the first lying bout tended $(P=0.097)$ to decrease with duration of deprivation (control $=21,2$ $\mathrm{h}=23,4-\mathrm{h}=10$; median $\mathrm{min} / \mathrm{cow})$. Because treated cows were recumbent (including lying ruminating) for a mean of 113 min less, respectively, during the deprivation period and for 46 min more, respectively, in the postdeprivation period, compared with control cows, the postdeprivation compensation for reduced lying during the deprivation period was incomplete at $40 \%$.

\section{Milk Production}

No treatment effects were detected on milk yield at any of the 4 milkings after imposition of treatment (Table 5).

\section{DISCUSSION}

\section{Continuous Recording}

Leg stomping, repositioning, weight-shifting, and head-swinging behaviors all increased in frequency when cows were deprived of an appropriate area for

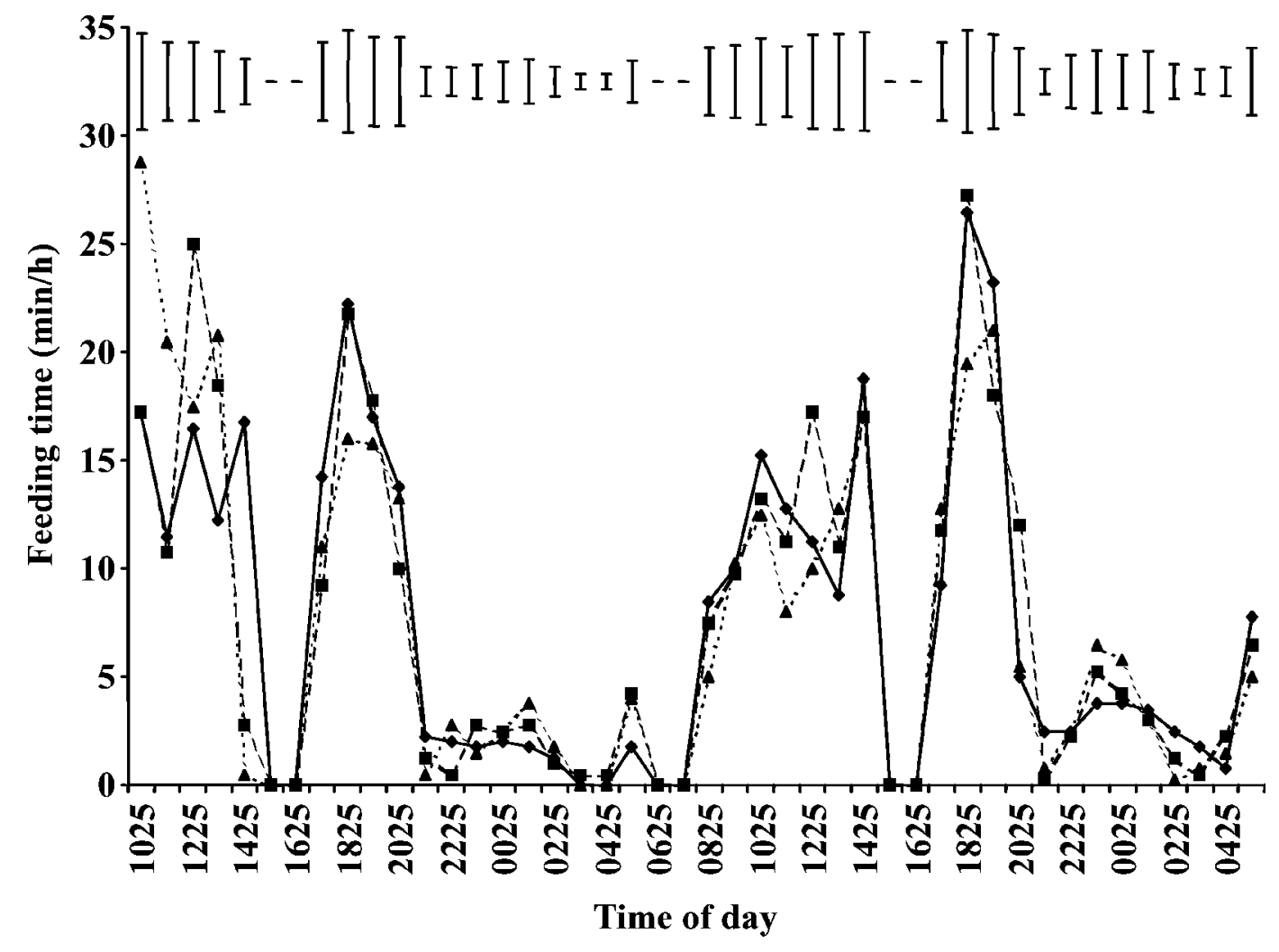

Figure 2. Mean time $(\mathrm{min} / \mathrm{h})$ spent feeding for cows in the control group ( $)$ and those deprived of the opportunity to lie down for $2 \mathrm{~h}$ (ם) or $4 \mathrm{~h}(\boldsymbol{\Delta})$. Bars indicate the standard errors of the difference between any 2 means. 


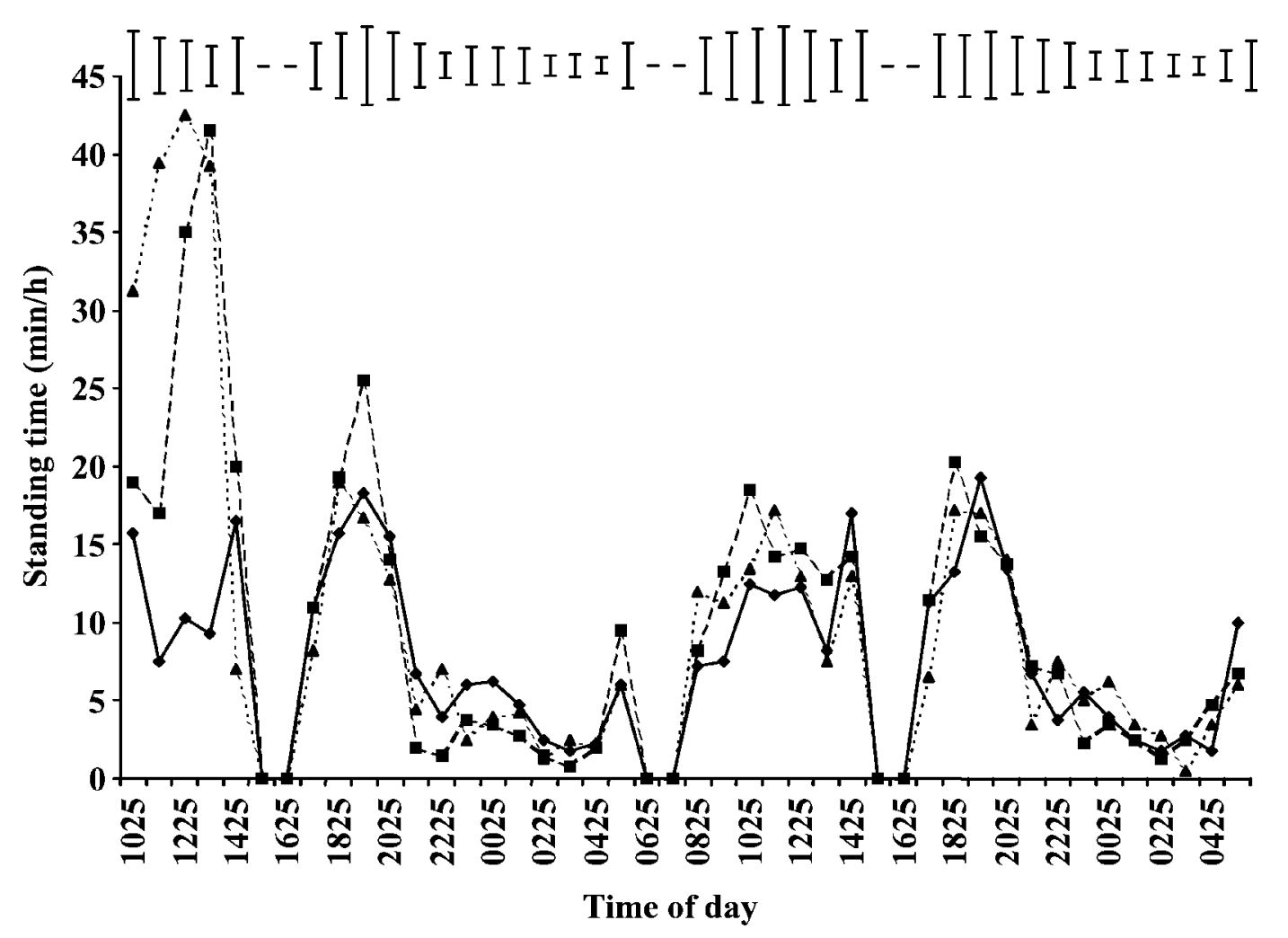

Figure 3. Mean time $(\mathrm{min} / \mathrm{h})$ spent standing without ruminating for cows in the control group ( $)$ and those deprived of the opportunity to lie down for $2 \mathrm{~h}(\boldsymbol{\square})$ or $4 \mathrm{~h}(\boldsymbol{\Delta})$. Bars indicate the standard errors of the difference between any 2 means.

lying. In addition, butting, although rarely performed, was principally observed in the lying-deprived cows. In previous studies, only weight shifting was noted as a behavioral response to lying deprivation in dairy cows (Ruckebusch, 1974; Hopster et al., 2002). Weight shifting was also observed in response to uncomfortable standing surfaces (Neveux et al., 2006). Leg stomping, repositioning, and weight-shifting behaviors may serve to temporarily reduce physical discomfort by alleviating strain on the legs and hooves. Head swinging and butting, on the other hand, were more likely to be behavioral expressions of discomfort (Sandem et al., 2002), which arose as a result of the cow's perception of not being able to lie down, only being able to lie on a hard surface, or due to the forced standing in a small area. Head swinging was not increased when both feed and lying time was restricted in similar circumstances (Cooper, 2003), perhaps because emotions arising from feed deprivation dominated. In this experiment, in addition to these effects, the increased butting activity in the 2and 4-h treatments may have been exacerbated by close confinement, as cattle are more aggressive when space allowance is reduced (Kondo et al., 1989). Because these behaviors increased in frequency during lying deprivation, the negative physical and psychological effects of lying prevention, and the motivation to lie, were probably cumulative. This suggests that long deprivation periods are more likely to result in a serious compromise of well-being than short periods of deprivation.

Lying deprivation did not affect time spent self grooming, unlike in other studies in which cattle deprived of lying groomed themselves more often and increased the frequency of oral behaviors (i.e., licking or chewing stall fixtures; Munksgaard and Simonsen, 1996; Munksgaard et al., 1999). Ruckebusch (1974) also observed oral activities in cows kept from lying for periods of up to $22 \mathrm{~h} / \mathrm{d}$. These behaviors may compensate for a lack of stimulation within a confined stall environment (Munksgaard and Simonsen, 1996), rather than as a direct result of the stress of lying prevention. These behaviors may be less common if the cows are not confined, for example, while at pasture (Redbo, 1990) or in the loose-housing situation of our experiment.

The correlations between sniffing the ground and self-licking and weight shifting indicated that the former might also be part of a complex of discomfort behaviors. Self-licking can be an indicator of stress (Munksgaard and Simonsen, 1996), thus the lying-deprived cows sniffed the ground, which is often a prelude to lying, but the thwarting of this behavior may have in- 


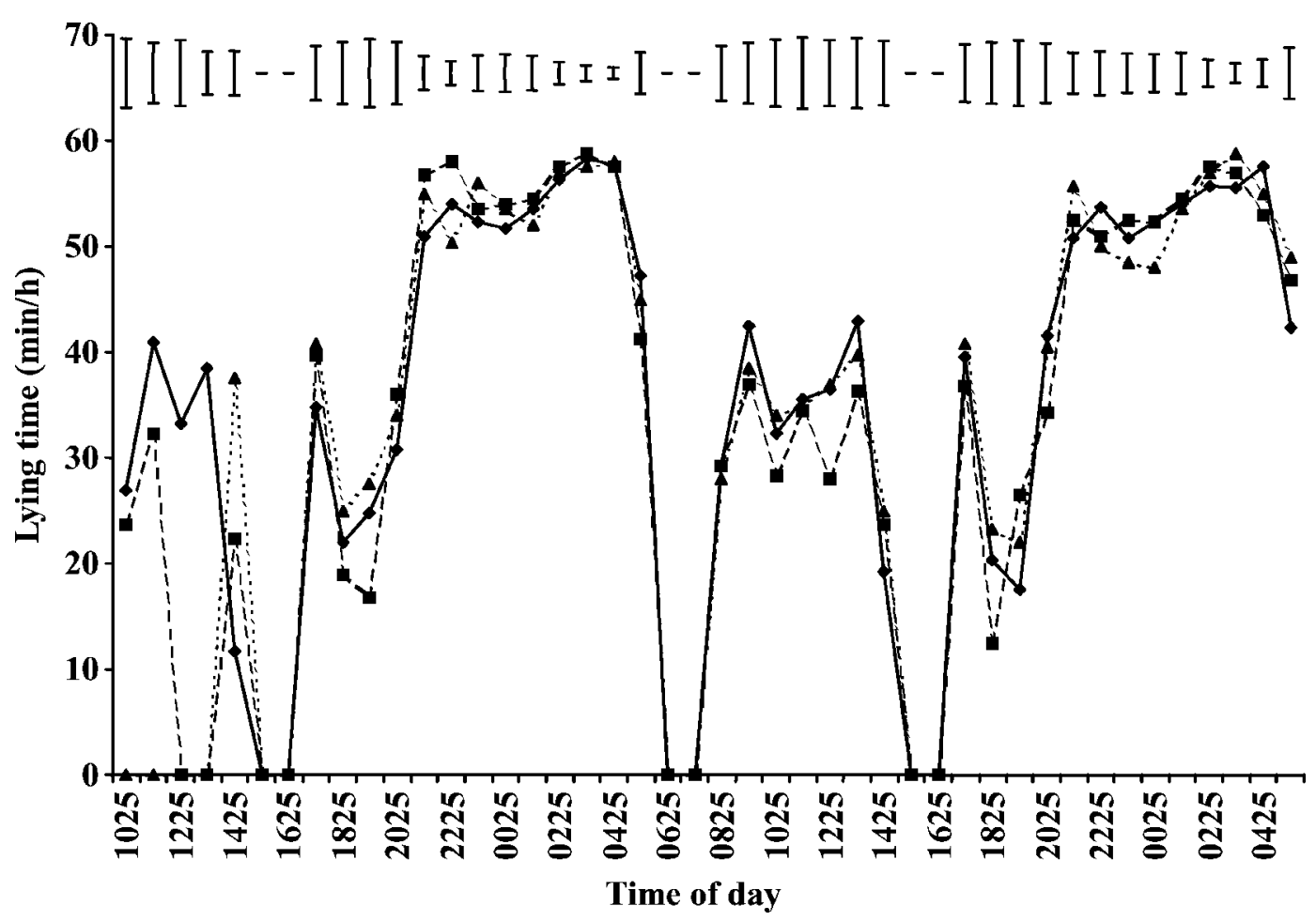

Figure 4. Mean time $(\mathrm{min} / \mathrm{h})$ spent lying without ruminating for cows in the control group $(\checkmark)$ and those deprived of the opportunity to

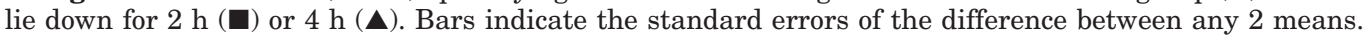

duced stress, manifested as licking behavior. However, because these behaviors were positively correlated in control cows, this behavior may have been derived from factors other than lying deprivation for cows in all treatments. The correlation between self-licking and head rubbing may indicate a common relief provided by skin massage. We speculate that head swinging and leg stomping may provide therapy by movement, self-narcotizing the cow during the stress of forced standing (Mendez and Mirea, 1998). It is not possible to attribute specific discomfort to the behaviors recorded, but future research could attempt to distinguish between physical and mental emotions by alleviating pain with analgesics or soft floors.

Table 5. Mean postdeprivation milk yields $(\mathrm{kg})$ for the first 4 milkings of cows in the control, 2-h, or 4-h lying-deprivation treatments

\begin{tabular}{lrrrrr}
\hline & \multicolumn{3}{c}{ Treatment } & & \\
\cline { 2 - 4 } Milking & Control & 2-h & 4-h & SED $^{1}$ & $P$ \\
\hline First p.m. & 8.8 & 9.3 & 8.6 & 0.37 & 0.32 \\
Second a.m. & 15.3 & 15.0 & 15.3 & 0.68 & 0.91 \\
Third p.m. & 8.9 & 11.0 & 8.2 & 0.44 & 0.95 \\
Fourth a.m. & 14.8 & 14.8 & 15.0 & 0.60 & 0.95 \\
\hline
\end{tabular}

${ }^{1}$ Standard error of the difference between any 2 means $(17 \mathrm{df})$.

\section{Instantaneous Recordings}

The lying-deprived cows primarily replaced lying time with standing not ruminating or feeding. In particular, they spent longer feeding in their first hour of deprivation, which is an expected high-priority behavior (Metz, 1985). Similarly, horses responded to the prevention of crib-biting by increased feeding (McGreevy and Nicol, 1998). Conversely, Ingvartsen et al. (1999) did not report increased feed intakes in lyingdeprived cows, but this may have been because cows were subjected to $14 \mathrm{~h}$ of lying deprivation daily for $10 \mathrm{wk}$, and any initial increase in feed intake went undetected. The negative feedback from postprandial satiety would render this response to lying deprivation short-lived by necessity. Munksgaard and Simonsen (1996), however, deprived cows of lying for $14 \mathrm{~h} / \mathrm{d}$ during $8 \mathrm{wk}$ and recorded an increased frequency of feeding.

Control cows were observed mainly ruminating while lying, and ruminating while standing was rarely observed during the entire deprivation period for controls and for the 2 -h treatment cows during the first $2 \mathrm{~h}$ (i.e., while not being forced to stand). This suggests that cows prefer to ruminate while lying, which is supported by Phillips and Leaver (1986), who reported that cows normally only spend approximately $1 \mathrm{~h} / \mathrm{d}$ ruminating 
while standing, but $6 \mathrm{~h} / \mathrm{d}$ ruminating while lying. Cows increased their time spent ruminating while standing with increasing deprivation time, which has been observed previously (Munksgaard and Simonsen, 1996; Munksgaard et al., 1999). This may be a consequence of having standing time available and no motivation or ability to perform other useful behaviors such as lying or feeding. Reduced ruminating time while standing in the first $2 \mathrm{~h}$ of deprivation for the 4-h treatment cows compared with the $2 \mathrm{~h}$ of deprivation for the 2 -h cows probably relates to the time of onset of lying deprivation (after the first feeding bout in 2-h cows, but during it for the 4-h treatment cows). Overall reduction in ruminating time during lying deprivation (mean of $30 \mathrm{~min}$ for the 2- and 4-h treatments) was probably because of substitution for feeding (mean increase of $25 \mathrm{~min}$ ).

Control cows were observed lying not ruminating for approximately equal amounts of time per hour (a total of $58 \mathrm{~min}$ ) while contemporary treated cows were deprived of lying. The 2-h cows also were observed lying not ruminating for approximately equal amounts of time in the first $2 \mathrm{~h}$, for a total of $21 \mathrm{~min}$, before their 2 -h lying deprivation period. This indicates that the cows were motivated to lie throughout the entire deprivation period. Although the 4-h treatment cows were deprived of lying for $4 \mathrm{~h}$, during the deprivation period control cows only spent a mean time of $142 \pm 8$ min lying, with and without ruminating. Thus, the 4 -h treatment cows were, in real terms, only deprived of lying for this amount of time, not a total of $4 \mathrm{~h}$. Likewise, the 2-h treated cows were only deprived of lying for $77 \mathrm{~min}$ in total (equal to the lying plus lying ruminating times for the controls during the third and fourth hour). Although this indicated the total time the treatment cows were likely to have been deprived of lying, there is likely to be an additive effect of not being able to choose when to lie and therefore unable to have recuperation periods (British Society for Animal Science, 1997).

\section{Postdeprivation Behavior}

Rescheduling of feeding behavior between the deprivation period and the postdeprivation period probably prevented feed intake being compromised in the longterm, although this has not been observed when dairy cows were deprived of lying for longer periods (Munksgaard and Simonsen, 1996; Ingvartsen et al., 1999). The greatest differences in feeding times for cows in the lying-deprived treatments and controls coincided with the greatest differences in lying times between these treatments $(1,2,5$, and $6 \mathrm{~h}$ postdeprivation), suggesting a trade-off between these behaviors. It also seemed necessary for the 4-h treatment cows to reduce their standing time during the first $8 \mathrm{~h}$ after depriva- tion, to increase their lying time. This indicates that adjusting feeding time alone was not sufficient to ensure an adequate increase in lying.

Prevention of lying for treated cows resulted in the greatest increase in lying time, compared with the controls, during the first $8 \mathrm{~h}$ compared with other 8 -h periods postdeprivation. The 2 - and 4 -h treated cows recovered 30\% (25 $\mathrm{min}$ ) and 46\% (65 min), respectively, of their lost lying time during this period. Similarly, Metz and Wierenga (1984) found that cows deprived of lying for $3 \mathrm{~h}$ compensated for $53 \%$ of their total lying deficit during the first $7 \mathrm{~h}$ postdeprivation. Metz (1985) found that cows recovered $58 \%$ of their 3 -h reduction in lying time within $10 \mathrm{~h}$. Fisher et al. (2003) reported that cows increased their lying times while at pasture for a $3-h$ period immediately after nearly $5 \mathrm{~h}$ of lying deprivation. Thus, cows voluntarily restore some of their lost lying time after only $2 \mathrm{~h}$ of lying deprivation, but a greater proportion of the lost lying time is voluntarily restored after 4 to $5 \mathrm{~h}$. This is further illustrated by the time to lie down during the first hour after milking postdeprivation, indicated by the latency to first lying bout, decreasing proportionately with increasing time spent deprived of lying. Hopster et al. (2002) observed longer lying bouts in dairy cows deprived of lying for $6 \mathrm{~h}$, but not 3 h. In that study, 3-h lying deprivation, however, had no effect on lying times of dairy cows during a 24-h period, but cows deprived of lying for $6 \mathrm{~h}$ lost $106 \mathrm{~min}$ of lying time, compared with control cows.

It took $29 \mathrm{~h}$ for the 4 -h treated cows to achieve approximately the same lying time as the 2 -h cows. None of the cows, however, in the 2- and 4-h treatments achieved the same lying time as controls during the 40$\mathrm{h}$ recovery period. Other studies concerned with the deprivation of lying in dairy cows also have observed incomplete compensation (Metz, 1985; Munksgaard and Simonsen, 1996; Munksgaard et al., 1999). Compared with controls and the 4 -h cows, the 2 -h cows had decreased time spent feeding during the lying-deprivation period, and a reduction in feeding time during the first $8 \mathrm{~h}$ postdeprivation. This might have made it difficult to give up any additional feeding time during the first $8 \mathrm{~h}$ to lie down. In a similar experiment, Hopster et al. (2002) found that dairy cows deprived of lying for $6 \mathrm{~h} / \mathrm{d}$ for $1 \mathrm{wk}$ took $3 \mathrm{~d}$ to completely compensate for their daily deprivation.

\section{CONCLUSIONS}

Isolated periods of standing, for example, while waiting for management procedures such as veterinary attention or when confined to concrete yards during periods of wet weather, are relatively common practice for dairy cows. However, preventing cows from lying down, 
even if only for $2 \mathrm{~h}$, poses a risk to cow comfort. When deprived of the opportunity to lie down, cows were more likely to stomp their legs and shift their weight. These changes in behavior indicate that cows find periods of forced standing uncomfortable. The negative effects of short-periods of lying deprivation were cumulative and, if repeated, may impair animal well-being in the long-term.

\section{ACKNOWLEDGMENTS}

The authors acknowledge the provision of a postgraduate studentship for MDC and facilities for the experiment by Moulton College, and a University Federation for Animal Welfare research grant.

\section{REFERENCES}

British Society for Animal Science. 1997. Animal Choices. Occasional Publication No. 20. University of Leeds, UK. Nottingham Univ. Press, Nottingham, UK.

Castle, M. E., and R. J. Halley. 1953. The grazing behaviour of dairy cattle at the National Institute of Research in Dairying. Anim. Behav. 1:139-143.

Chamberlain, A. T., and J. M. Wilkinson. 1996. Feeding the Dairy Cow. Chalcombe Publications, Welton, Lincoln, UK.

Chaplin, S., and L. Munksgaard. 2001. Evaluation of a simple method for assessment of rising behaviour in tethered dairy cows. Anim. Sci. 72:191-197.

Cooper, M. 2003. The behavioural requirements of high-yielding dairy cows. PhD Thesis. Open University, Milton Keynes, UK.

Fisher, A. D., M. Stewart, G. A. Verkerk, C. J. Morrow, and L. R. Mathews. 2003. The effects of surface type on lying behaviour and stress responses of dairy cows during periodic weather-induced removal from pasture. Appl. Anim. Behav. Sci. 81:1-11.

Fregonesi, J. A., and D. Leaver. 2001. Behaviour, performance and health indicators of welfare for dairy cows housed in strawyard and cubicle systems. Livest. Prod. Sci. 68:205-216.

Haley, D. B., J. Rushen, and A. M. de Passille. 2000. Behavioural indicators of cow comfort: Activity and resting behaviour of dairy cows in two types of housing. Can. J. Anim. Sci. 80: 257-263.

Hart, B. L. 1988. Biological basis of the behaviour of sick animals. Neurosci. Behav. Rev. 12:123-137.

Hopster, H., G.-N. Hermans, B. Engel, and J. T. N. Van der Werf. 2002. Behavioural and physiological consequences of deprivation from nightly lying in dairy cows. Page 143 in Proc. 36th Int. Congr. Int. Soc. Appl. Ethol., Zan am Zee, the Netherlands.

Houpt, K., T. R. Houpt, J. L. Johnson, H. N. Erb, and S. C. Yeon. 2001. The effect of exercise deprivation on the behaviour and physiology of straight stall confined pregnant mares. Anim. Welf. 10:257-267.

Ingvartsen, K. L., L. Munksgaard, V. K. M. Nielsen, and L. Pedersen. 1999. Responses of repeated deprivation of lying down on feed intake, performance and blood hormone concentration in growing bulls. Acta Agric. Scand. A Anim. Sci. 49:260-265.
Jensen, M. B., L. J. Pedersen, and L. Munksgaard. 2005. The effect of reward duration on demand functions for rest in dairy heifers and lying requirements as measured by demand functions. Appl. Anim. Behav. Sci. 90:207-217.

Kondo, S., J. Sekine, M. Okubo, and Y. Asahida. 1989. The effect of group size and space allowance on agonistic and spacing behavior of cattle. Appl. Anim. Behav. Sci. 24:127-135.

Lowman, B. G., N. Scott, and S. Sommerville. 1973. Condition scoring of cattle. Bull. no. 6, East of Scotland College of Agriculture, Edinburgh, UK.

McGreevy, P. D., and C. J. Nicol. 1998. The effect of short-term prevention on the subsequent rate of crib-biting in thoroughbred horses. Equine Clin. Behav. 27:30-34.

Mendez, M. F., and A. Mirea. 1998. Adult head-banging and stereotypic movement disorders. Mov. Disord. 13:825-828.

Metz, J. 1985. The reaction of cows to a short-term deprivation of lying. Appl. Anim. Behav. Sci. 13:301-307.

Metz, J. H., and H. K. Wierenga. 1984. Spatial requirements and lying behaviour of cows in loose housing systems. Pages 179-183 in Proc. Int. Congr. Appl. Ethol. Farm Anim., Kiel, Germany. J. Unshelm, G. van Putten, and K. Zeeb, ed. Kuratorium fur Technik and Bauwesen in der Landwirtschaft, Damstadt, Germany.

Munksgaard, L., L. Ingvartsen, L. J. Pedersen, and V. K. M. Nielsen. 1999. Deprivation of lying down affects behaviour and pituitaryadrenal axis responses in young bulls. Acta Agric. Scand. A Anim. Sci. 49:172-178.

Munksgaard, L., and P. Lovendahl. 1993. Effect of social and physical stressors on growth hormone levels in dairy cows. Can. J. Anim. Sci. 73:847-853.

Munksgaard, L., and H. Simonsen. 1996. Behavioural and pituitaryadrenal axis responses of dairy cows to social isolation and deprivation of lying down. J. Anim. Sci. 74:769-778.

Neveux, S., D. M. Weary, J. Rushen, M. A. G. von Keyserlingk, and A. M. de Passillé. 2006. Hoof discomfort changes how dairy cattle distribute their body weight. J. Dairy Sci. 89:2503-2509.

Phillips, C. J. C., and J. D. Leaver. 1986. The effect of forage supplementation on the behaviour of grazing dairy cows. Appl. Anim. Behav. Sci. 16:233-247.

Phillips, C. J. C., and S. A. Schofield. 1994. The effect of cubicle and strawyard housing on behaviour, production and hoof health of dairy cows. Anim. Welf. 3:37-44.

Redbo, I. 1990. Changes in duration and frequency of sterotypies and their adjoining behaviours in heifers, before, during and after the grazing period. Appl. Anim. Behav. Sci. 26:57-67.

Ruckebusch, Y. 1974. Sleep deprivation in cattle. Brain Res. 78:495-499

Sandem, A. I., B. O. Braastad, and K. E. Boe. 2002. Eye white may indicate emotional state on a frustration-contentedness axis in dairy cows. Appl. Anim. Behav. Sci. 79:1-10.

Singh, S. S., W. R. Ward, J. W. Lautenbach, J. W. Hughes, and R. D. Murray. 1993. Behavior of first lactation and adult dairy cows while housed and at pasture and its relationship with sole lesions. Vet. Rec. 133:469-474

Veris, J., Z. Bajnar, and J. Navratil. 1980. Daily behaviour of dairy cows in groups of different size and at different stages of lactation under conditions of free housing in a large cowshed with cubicles. Dairy Sci. Abstr. 46:258.

Wierenga, H. K., and H. Hopster. 1990. The significance of cubicles for the behaviour of dairy cows. Appl. Anim. Behav. Sci. 26:309-337. 